\title{
¿Quién es el "politólogo", según Aristóteles? Introducción al primer número de la revista «Pegé / Fons»
}

\author{
MiCHELE CURNIS \\ Universidad Carlos III de Madrid \\ mcurnis@inst.uc3m.es
}

El último párrafo de la Ética a Nicómaco (X 9) está dedicado a la relación entre la ética y la política, a partir de la cuestión de lo que se origina la práctica de las virtudes ( $\mathrm{y}$, a la inversa, de lo que inhibe la práctica de acciones reprobables). Aristóteles cree que existe un tipo de carácter adecuado a la virtud, capaz de amarla como para practicarla; sin embargo para este carácter, aún más que para su enseñanza (es decir, los aspectos teóricos, en que se basa la redacción de la misma Ética), es esencial la existencia de leyes que determinen las actividades y la educación de la juventud. De hecho, «los actos más virtuosos se hacen sobre la base de las buenas leyes» ( $E N \mathrm{X}$ 9, 1180a 34 s.): es gracias a estas leyes que los hombres se vuelven virtuosos $(1180 \mathrm{~b} 25)$. El razonamiento conduce a la conclusión de que sólo el titular de los conocimientos de la ley y la legislación, es decir el político, puede preservar el conocimiento de la virtud y de su enseñanza. Es en este sentido, precisamente, que surge la cuestión de su formación política, ya que debe actuar, en lugar de enseñar, y que, por eso, rara vez logra transmitir a los demás su $\tau \chi_{\chi} \chi \nu \eta$ específica. Así como no se convierten en médicos con sólo el estudio de los manuales, de la misma manera - dice Aristóteles - no se convierten los hombres en políticos con sólo el estudio de las leyes existentes. La $\tau \epsilon ́ \chi \chi \nu \eta$

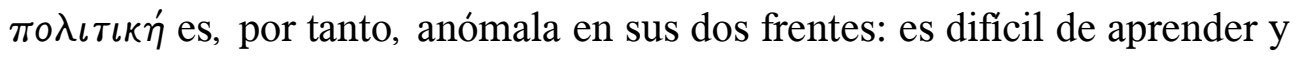
es difícil identificar quién puede enseñarla. El estudio de la legislación se convierte en el nuevo objetivo del filósofo en las páginas finales de la Ética a Nicómaco, como enlace entre el conocimiento de la virtud y de su 
práctica en el ámbito social. En términos más generales, la perspectiva de Aristóteles quiere lograr un análisis completo del modus vivendi del animal social, y este es el objetivo de su escritura política.

No es una técnica cuyo tratamiento sea exclusivo de la política, puesto que ya en el primer libro de la Retórica Aristóteles le exige al orador saber «tutta la gamma dei regimi politici, e insieme delle abitudini, delle tradizioni, degli interessi che a ciascuno di essi si correlano»; y además de

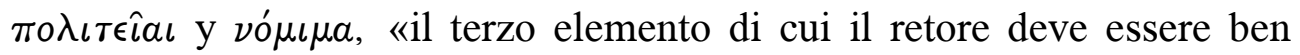
consapevole è costituito da ciò che è utile al regime politico in vista della sua conservazione» ${ }^{1}$. Sobre la base de estas observaciones, no es de extrañar que el final del tratado dedicado a Nicómaco se convierta en el preludio del análisis político, es decir, en el comienzo de otro tratado; las últimas líneas de la Ética marcan realmente el comienzo de la Política sin solución de continuidad. Sin embargo, la lectura sinóptica de las últimas páginas de Ética Nicomaquea y Política no permite establecer una efectiva continuidad temática o metodológica, muy probablemente porque el primer libro actual del último tratado mencionado no fue el principio real de la obra aristotélica original. Más allá de los problemas de composición y desplazamiento de los libros, de todas maneras, cabe destacar que la causa última de la redacción de la Política ha de ser rastreada en la investigación ética y que la $\tau$ t́́ $\chi \nu \eta$ correspondiente al nuevo tratado es especial en comparación con las otras por más razones.

En el marco de una lectura intertextual y actualizada a los últimos avances de los estudios aristotélicos, la revista «Pegé / Fons» dedica su primer número a una colección de estudios sobre la Política y algunos problemas que suscita su lectura. Estos estudios son el resultado de un congreso internacional del "Collegium Politicum" que se celebró en

Las dos citas proceden de Aristotele, Retorica. Introduzione, traduzione e commento di S. GaStALDI, Carocci Editore, Roma 2014, 404; véase la reseña del libro en este fascículo (164-169). 
Madrid en $2012^{2}$, pero pueden ocurrir como una tendencia general de las investigaciones exegéticas internacionales acerca de la obra. En los últimos años el tratado de Aristóteles, de hecho, ha sido un foco creciente de interés, como resulta de reuniones científicas $^{3}$, nuevas ediciones ${ }^{4}$, conferencias y sobre todo estudios e investigaciones específicos ${ }^{5}$. Sería

2 XII Meeting of the "Collegium Politicum". Madrid 25-26" May 2012, Instituto de Estudios Clásicos "Lucio Anneo Séneca” - Universidad Carlos III de Madrid.

3 Cabe destacar, por ejemplo, el congreso internacional "La armonía del conflicto. Los fundamentos aristotélicos de la política", Madrid, 8 y 9 de octubre de 2008, Instituto de Estudios Clásicos "Lucio Anneo Séneca" - Universidad Carlos III de Madrid.

4 Cf., e.g., Aristoteles, Politik. Buch I, übersetzt und erläutert von E. SCHüTrumPF, Akademie Verlag, Berlin 1991; Aristoteles, Politik, Buch II und Buch III, übersetzt und erläutert von E. SCHüTrumpF, Akademie Verlag, Berlin 1991; Aristoteles, Politik, III, Buch IV-VI, übersetz und eingeleitet von E. SCHüTRUMPF, erläutert von E. SCHütrumpF und H.-J. GehrKe, Akademie Verlag, Berlin 1996; Aristoteles, Politik, IV, Buch VII-VIII, über die beste Verfassung, übersetz und erläutert von E. SCHüTRUMPF, Akademie Verlag, Berlin 2005. Ediciones con discusión crítica (aunque mínima) del texto griego son: Aristotle's Politics, Translated and with an Introduction, Notes and Glossary by C. LORD, University of Chicago Press, Chicago-London $2013^{2}$ (1984); Aristotele, Politica, Introduzioni di L. CANFORA e R. Kraut, Traduzione di R. Radice e T. Gargiulo, Commento di T. J. Saunders e R. Robinson, Fondazione Lorenzo Valla - A. Mondadori, I-II, Milano 2014-2015. Por la edición crítica dirigida por L. Bertelli y M. Moggi cf. infra la n. 7.

5 Véanse, por ejemplo, sólo en el siglo XXI, R. Kraut, S. SKUltety (eds.), Aristotle's Politics. Critical Essays, Rowman \& Littlefield, Oxford 2005; L. E. Goodman, R. B. TALisse (eds.), Aristotle's Politics Today, State University of New York Press, New York 2007; J. A. Swanson, C. D. Corbin (eds.), Aristotle's Politics, Continuum, London-New York 2009; E. GARVER, Aristotle's Politics. Living Well and Living Together, University of Chicago Press, Chicago-London 2011; Th. A. PAngle, Aristotle's Teaching in the Politics, University of Chicago Press, Chicago-London 2013; M. Deslauriers, P. Destrée (eds.), The Cambridge Companion to Aristotle's Politics, Cambridge University Press, Cambridge 2013; M. H. HANSEN, Reflections on Aristotle's Politics, Museum Tusculanum Press - University of Copenhagen, Copenhagen 2013; Th. Lockwood, Th. Samaras (eds.), Aristotle's Politics. A Critical Guide, Cambridge University Press, Cambridge 2015. 
demasiado fácil, y sin duda simplista, interpretar este "renacimiento" de estudios como un síntoma de la crisis de los modelos políticos que caracteriza la segunda mitad del siglo XX en el mundo occidental, y que en los albores del siglo XXI se siente más agudamente. Un hecho, sin embargo, parece aceptable y deseable: «L'approccio al pensiero di Aristotele esige da sempre una raffinata preparazione: non solo per accedere alla multiforme complessità del suo pensiero, ma anche - e forse soprattutto - perché l'uso specialistico del linguaggio che connota la ricerca dello Stagirita possa essere di vantaggio e non di ostacolo alla comprensione» ${ }^{6}$. En el caso de la Política, en particular, sólo la preparación en varios frentes, la pluralidad de conocimientos, y por lo tanto la «collaborazione interdisciplinare» ${ }^{7}$ entre investigadores de diferentes orígenes, pueden permitir entender con la percepción correcta y adecuada aquel «uso specialistico del linguaggio» que caracteriza las


exegéticas confiables que la estructura aristotélica del mejor sistema de gobierno $(\pi \circ \lambda \iota \tau \epsilon i a)$ sigue siendo una fuente de controversia; como enseñan distintamente los ensayos de «Pegé», incluso hoy en día están abiertas más perspectivas de investigación sobre el modelo político que Aristóteles indica como forma mejor y más propicia para la armonía de los ciudadanos. La urgente necesidad de entender estas perspectivas se

6 E. Cattanei, F. Fronterotta, S. Maso, Introduzione, en: E. Cattanei, F. Fronterotta, S. Maso (eds.), Studi su Aristotele e l'Aristotelismo ("Studi di Storia della Filosofia Antica" 1), Edizioni di Storia e Letteratura, Roma 2015, VIII.

L. Bertelli, M. Moggi, Presentazione dell'opera, en: Aristotele. La Politica, Direzione di L. B. e M. M., I, Istituto Italiano per la Storia Antica - «L'Erma» di Bretschneider, Roma 2011, VI (de esta nueva edición crítica de la Política, con texto griego y aparatos, traducción y comentario en italiano, han parecido los volúmenes I [libro I], II [libro II, Roma 2012], III [libro III, Roma 2013], IV [libro IV, Roma 2014], V [libros V-VI, Roma 2016]). 


\section{¿Quién es el "politólogo", según Aristóteles?}

identifica con una necesidad parecida de aplicarlas, incluso en tipos de sociedad tan diversas como las contemporáneas ${ }^{8}$.

La percepción correcta del mensaje político de Aristóteles, sin embargo, empieza con la recepción crítica de la obra, es decir, con la presentación filológica del texto: sin una edición de referencia, respetuosa de la tradición manuscrita y los muchos problemas que vienen con ella, no se puede lograr resultados exegéticos plenamente compartibles. El texto griego establecido por David Ross (1957) puede considerarse, de hecho, como bastante anticuado (1957), equipado con un aparato de información ínfimo comparado con la complejidad de la situación manuscrita y además es un texto que incorpora muchas conjeturas demasiado simplistas. Sin embargo, es también el más utilizado por los traductores, comentaristas y exégetas; ni la edición crítica de Alois Dreizehnter (1970) ni la de Jean Aubonnet (1960-1989), las dos mucho más ricas en referencias documentales, han logrado establecerse a nivel internacional como textos de referencia.

Con respecto a la relación que une la Política con los tratados éticos, el lector juzguará consistente que el fascículo de Pegé se abra con un ensayo de Veronika Konrádová centrado en el último libro de la Ética a Nicómaco

8 En los últimos años se encuentran cada vez menos estudios acerca de la tradición textual griega o latina de la Política: véanse sin embargo R. LAMBERTINI, Lo studio e la ricezione della Politica tra XIII e XIV secolo, en: C. DOLCINI (ed.), II pensiero politico dell'età antica e medioevale. Dalla polis alla formazione degli Stati europei, Utet, Torino 2000, 145-173; M. CURNIS, Le parole per il potere: Strozzi, Bruni, Filelfo e la Politica di Aristotele, en: E. BONA, M. CURNIS (eds.), Linguaggi del potere, poteri del linguaggio - Langages du pouvoir, pouvoirs du langage. Atti del convegno PARSA, Torino 6-8 novembre 2008, Edizioni dell'Orso, Alessandria 2010, 417-437; IDEM, II codice Marc. lat. 2527, Muretus e la Politica di Aristotele, en: A. BALBO, F. BeSSONE, E. MalaspinA (eds.), 'Tanti affetti in tal momento'. Studi in onore di Giovanna Garbarino, Edizioni dell'Orso, Alessandria 2011, 297-304; E. SCHüTRUMPF, The earliest translations of Aristotle's Politics and the creation of political terminology, Fink, Paderborn 2014; L. LANZA, "Ei autem qui de politia considerat". Aristotele nel pensiero politico medievale, Brepols, Turnhout 2015. 
y el análisis de la vida humana y divina. La investigadora observa que el libro trata la distinción entre la vida política y la vida filosófica, pero no como dos modelos diferentes entre los que el hombre tiene que elegir, porque se excluyen entre sí, sino como perspectivas que se comunican. La vida política que enfrenta el final de la Ética, por el contrario, ya permite el logro de la contemplación filosófica, y sería un motivo adicional para mantener la coherencia entre los dos tratados. Con esta perspectiva, el artículo de Konrádová, a pesar de estar dedicado sustancialmente a la Ética Nicomaquea, aparece como la más adecuada introducción a la discusión sobre la Política.

Se ocupa de prácticas específicas de la vida social también el ensayo de Arianna Fermani, dedicado a un tema principal del primer libro de la Política como la crematística (especialmente con respecto a los capítulos 8-11). La percepción correcta de esta práctica depende de una definición dual disponible en las páginas de Aristóteles: en una primera forma, la crematística puede explicarse como un deseo canalizado, gestionado y organizado por la sabiduría, en vista de un fin ulterior, pero cuando el deseo de riqueza se pone como fin en sí mismo, insaciable, ilimitado, que ya no responde a los mandamientos de la sabiduría, se trata de una crematística equivocada, y hay que rechazarla. La búsqueda de la riqueza no es una mala acción, siempre y cuando esté adecuadamente enmarcada

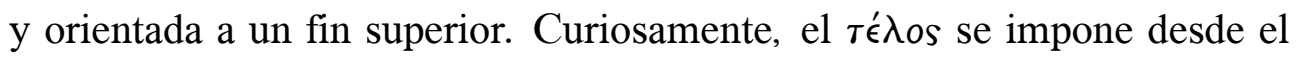
primer libro de la Política como un horizonte indispensable de toda la acción social y por eso el lector tiene que conectarlo (por ejemplo, a través de la crematística) al tema del "vivir bien", que Aristóteles presenta como fin de la vida social misma.

También el articulado ensayo de Manuel Knoll procesa los indicios de otro de los temas específicos dentro de la Política (justicia distributiva, en los libros IV-VI) para estudiar una cuestión mucho más amplia, como las diferentes formas de constitución; la variedad de regímenes políticos, según Knoll, sería de hecho el resultado de las diferentes concepciones de 
la justicia distributiva. Dado que la forma preferida por Aristóteles de justicia distributiva es la aristocrática, Knoll sostiene que, en última instancia, la mejor forma de ciudad-estado en los libros VI-VIII debería

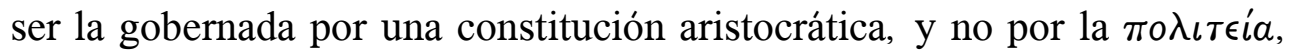
como generalmente se afirma. Al mismo argumento se conecta el estudio de Elena Irrera, que tiene como objetivo analizar las consideraciones aristotélicas de los regímenes aristocráticos basándose en cuatro grandes ejes temáticos: tipo perfecto de constitución, tipo realizado a partir de una mezcla estudiada de las clases sociales, tipo de $\pi \circ \lambda_{\iota} \tau \epsilon i a$ que tiende a la oligarquía y para finalizar tipo que tiende a la aristocracia. Esta última es aquella en la que la investigadora más se centra, para presentar una hipótesis en algunos aspectos parecida a la de Knoll, es decir que en condiciones políticas menos que ideales Aristóteles cree que la mejor

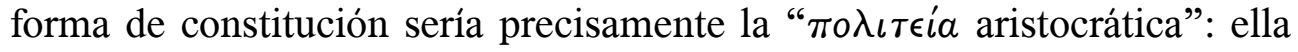
sí, mejor que los otros modelos, cumple con los requisitos de estabilidad, concordia, armonía entre gobernantes y gobernados.

Jakub Jinek elabora su estudio a partir de un convencimiento aristotélico que une la ciudad con su constitución: si el objetivo de una ciudad, que se caracteriza por la multiplicidad de formas y existencias, es el "vivir bien" en sociedad, la mejor constitución para esta ciudad depende precisamente de las diferentes formas de vida, y en particular de la distinción entre las virtudes de un buen hombre y las del buen ciudadano. La diferencia cualitativa entre estas virtudes también se puede encontrar en la comparación de las distintas constituciones políticas.

La coherencia global del pensamiento aristotélico y, por lo tanto, el problema de la unidad de la Política desde una perspectiva histórica y textual también pueden ser investigados a la luz de una evolución orgánica («organische Entwicklung») de las ideas del filósofo dentro de las diversas obras, de acuerdo con la famosa teoría de Werner Jaeger que data de 1923. El ensayo de Lucio Bertelli está precisamente dedicado a la reconstrucción de las reacciones a la publicación de esta teoría, sus 
antecedentes y su reflejo en las debilidades que ella implica, incluso en el análisis contemporáneo.

El recién desaparecido Aleš Havlíček, a quien Jakub Jinek dedica una nota in memoriam a final del fascículo, traza la herencia de unas investigaciones aristotélicas de la Política en el Leviatán de Thomas Hobbes. El estudioso advierte que la definición del hombre como animal "social" va a desarrollarse en Hobbes con la caracterización de los opuestos extremos, o sea del hombre "natural" y del hombre "artefacto", los dos utilizados en lugar del adjetivo "político". Gracias al estudio de Havlíček el primer número de «Pegé» se cierra con una perspectiva diacrónica, presentando una vez más la herencia del pensamiento político antiguo en los tiempos modernos en clave no tanto de "supervivencia", sino de fructífera y estimulante "vitalidad". 